\title{
LA JERARQUÍA DE MONEDAS NACIONALES Y LOS PROBLEMAS FINANCIEROS ACTUALES
}

Pilar Piquêk

Dalabras como pánicos, crisis, fallas de mercado, desequilibrio, rescate bancario, endeudamiento y asimetrías de poder son parte del lenguaje cotidiano. Las leemos en los diarios, las escuchamos en la radio y la televisión y las usamos en reuniones y conversaciones. Todas ellas denotan hechos permanentes en el mundo actual. Y, por paradójico que parezca, el corpus de conocimientos que condensa la "sabiduría económica convencional" solo las evoca para referirse a hechos "anómalos". En su mundo, donde operan las leyes de equilibrio, desequilibrios como las crisis son sucesos transitorios que se disipan en un proceso intrínseco de ajuste, en el que no hay compradores ni vendedores "estafados", ni empresas que aventajen a otras y obtengan ganancias extraordinarias.

E1 correlato político-económico de ese mundo es un conjunto de Estados nación donde no hay ningún tipo de imposición y todos se benefician del comercio y los flujos internacionales de dinero. La moneda nacional cumple las funciones de patrón de precios, medio de circulación y de pago, reserva de valor y equivalente de todos los bienes dentro de sus fronteras. Fuera de ellas circula e impera el "dinero mundial". La tasa de cambio y la oferta monetaria nacional y "natural" son resultado del equilibrio en el comercio mundial.

Esa imagen limita la comprensión de los procesos económicos actuales. No obstante, la literatura supera los lindes de dicha imagen, por

* Licenciada en Economía, becaria doctoral del CEPED, Facultad de Ciencias Económicas, Universidad de Buenos Aires, Buenos Aires, Argentina, [pilarpique@ gmail.com]. Fecha de recepción: 27 de agosto de 2014, fecha de modificación: 9 de septiembre de 2015, fecha de aceptación: 12 de mayo de 2016. Sugerencia de citación: Piqué, P. "La jerarquía de monedas nacionales y los problemas financieros actuales", Revista de Economía Institucional 18, 34, 2016, pp. 69-85. DOI: http:// dx.doi.org/10.18601/01245996.v18n34.06 
el esfuerzo serio y sistemático de numerosos economistas que intentan ampliar el horizonte, constatan que los fenómenos mencionados no son anómalos y no escapan al entendimiento, y buscan revertir la coyuntura actual, provocada por la crisis que estalló a mediados de 2007 y aún tiene graves consecuencias.

Este artículo explora algunos de los grandes problemas financieros actuales a partir de un rasgo central del sistema monetario y financiero contemporáneo: la capacidad del dólar para desempeñar las funciones de dinero mundial. Con ese fin recurre al concepto de jerarquía de monedas nacionales para distinguir la estructura monetaria y financiera jerárquica prevaleciente y entenderla en su relación con los rasgos centrales del capitalismo actual. La exploración es guiada por dos grupos de preguntas:

1. ¿Qué problema práctico e histórico se intenta plantear y entender con el concepto de jerarquía de monedas nacionales? ¿Qué relación hay entre ese concepto y el capitalismo actual?

2. ¿Qué posibilidades of rece para articular en forma coherente tres grandes problemas: los desequilibrios mundiales de cuenta corriente, la incapacidad de la mayoría de los bancos centrales para cumplir su misión, y los rasgos principales de la crisis reciente?

Se intenta responderlas mediante un enfoque analítico que reúne varios problemas que la literatura suele tratar en forma aislada. Este análisis quizá suscite otras preguntas que podrían abordar estudios futuros que combinen la contrastación empírica y la elaboración de enfoques alternativos. En la primera sección se muestra que el concepto de jerarquía de monedas nacionales puede reunir aportes de la teoría del dinero mundial e integrarlos en una teoría del capital que represente la dinámica del capitalismo actual. En la segunda se analizan los desequilibrios mundiales de cuenta corriente y el curso que imprimieron al sistema financiero; la conexión entre esos desequilibrios y el cambio de objetivos de la banca central (manejar las reservas y la tasa de cambio según el nivel de desarrollo de su economía) en el marco del sistema de reservas basado en el dólar; y el vínculo entre estos problemas y el aspecto financiero de la crisis; los problemas del sistema financiero actual y las limitaciones de las entidades financieras para emprender una reforma estructural.

Si bien los procesos que se examinan se iniciaron a comienzos de los años setenta, el análisis se centra en las características que adquirieron en los últimos quince años. Esas características -y la crisis reciente, la manifestación más alarmante de los graves problemas del orden vigente- anuncian el ocaso de una época. 


\section{JERARQUÍA DE MONEDAS Y DIFERENCIACIÓN DEL CAPITAL}

\section{CONTRIBUCIONES DE LA LITERATURA}

Desde los años cuarenta, la moneda pasó a ser objeto de la naciente macroeconomía (Woodford, 1999). Al concepto de moneda se le imprimió un refinamiento analítico y técnico amoldado a un conjunto de supuestos ajenos a la tradición clásica y neoclásica: la moneda se equiparó a una serie de variables macroeconómicas contables de corto plazo en las que tienen impacto las decisiones de la autoridad monetaria, y se la restringió a un ámbito nacional indiferenciado y por ello aplicable a cualquier economía nacional.

Estos supuestos correspondían a percepciones compartidas desde la Gran Depresión hasta finales de la segunda posguerra, entre ellas, que el sistema capitalista no conducía per se al progreso general sino a recesiones prolongadas. De allí la necesidad de concebir una política económica que superara esas limitaciones, que permitiera salir de la crisis y encaminarse hacia el progreso ciñéndose a un espacio nacional (Keynes, 1936) ${ }^{1}$. La limitación del problema a la dimensión nacional suponía la autonomía de las economías nacionales, incluida la dimensión monetaria, es decir, la soberanía monetaria de las naciones.

En retrospectiva, las percepciones asociadas al enfoque macroeconómico tenían limitaciones prácticas $a b$ ovo. En lo que respecta a la limitada soberanía monetaria, ya se manifestaban en el papel de la moneda estadounidense mientras prevalecieron los acuerdos de Bretton Woods. En esa época, todas las monedas nacionales debían estar vinculadas al dólar; y este, "atado" a un precio fijo en oro. Valéry Giscard d'Estaing, entonces ministro de Economía de Charles de Gaulle, acuñó la expresión "privilegio exorbitante" para referirse a las atribuciones del dólar, que no poseían otras monedas. Eichengreen resume el alcance de tales atribuciones:

\footnotetext{
En tanto que los bancos extranjeros y las firmas evalúan la conveniencia de los valores en dólares, desean pagar más para obtenerlos. Equivalentemente, la tasa de interés requerida para poseerlos es menor. El efecto es sustancial: la tasa de interés que Estados Unidos debe pagar para sus compromisos externos es dos o tres por ciento menor que la tasa de retorno de sus inversiones externas. Estados Unidos puede incurrir en déficit en el monto de esta diferencia, importando más de lo que exporta y consumiendo más de lo que produce año tras año sin endeudarse con el resto del mundo. $O$ puede alzar en brazos a compañías extranjeras en ese monto como resultado del estatus singular del dólar como moneda mundial $(2011,4)$.
}

${ }^{1}$ Con base en el modelo IS-LM se prescribían políticas fiscales y monetarias
"expansivas" para estimular la inversión y, por ende, ampliar el producto y el empleo.

Revista de Economía Institucional, vol. i8, N. ${ }^{3}$ 34, Primer semestre/20i6, pp. 69-85 
$\mathrm{E} 1$ hecho de que el dólar oficiara como "dinero mundial" puso de relieve su licencia para funcionar como medio de pago y de reserva de valor "con privilegios" a nivel internacional. Esos "privilegios" dejaron una nueva impronta en el sistema monetario y financiero internacional que se mantendría y ampliaría con el fin de Bretton Woods, al decretarse "la inconvertibilidad del dólar al oro". Después del fin de esos acuerdos hubo una expansión sin precedentes de los flujos transnacionales de capital financiero, que restó aún más credibilidad a la presunta soberanía monetaria y llevó a que diversos autores abordaran el tema monetario y financiero deshaciéndose de los dos supuestos ya mencionados ${ }^{2}$.

Entre los estudios sobre dinero internacional que intentaron responder a esa coyuntura, tres nutren el marco conceptual de este artículo. E1 de Olivera (1983), donde el economista argentino argumentó que, bajo el supuesto de que la cantidad de dinero mundial se ajusta a su demanda, solo un país puede fijar su oferta monetaria y su tasa de cambio, logrando (y, cabe añadir, consolidando) así un papel hegemónico en el sistema monetario mundial. El de García et al. (2008), que presenta conceptos concretos que complementan el trabajo de Olivera y describe el nuevo escenario monetario internacional con ayuda de indicadores cuantitativos derivados del balance de los bancos centrales. Y el cual argumenta que el sistema monetario actual es asimétrico, pues divide el mundo en economías emisoras de reservas (EER) y economías receptoras de reservas (ERR) ${ }^{3}$. La asimetría consiste en que, al fijar las tasas de interés, los bancos centrales de las ERR deben considerar las inevitables fluctuaciones del volumen de reservas internacionales y de la tasa de cambio, lo que no es necesario para los bancos centrales de las EER. Los bancos centrales de las ERR deben garantizar un nivel de divisas mínimo porque ni el crédito interno privado ni el dinero base del Estado sirven para hacer pagos internacionales porque la moneda nacional no es de circulación internacional. La tensión para mantener cierto nivel de reservas en divisas afecta la tasa de cambio. Las EER tienen mayor libertad para

\footnotetext{
${ }^{2}$ Lo que suscitó intensas discusiones en la misma macroeconomía, en las que ganaron peso quienes sostenían que las políticas expansivas no eran efectivas, es decir, que no tenían efectos reales (Lucas, 1976; Sargent y Wallace, 1975; Kydland y Prescott, 1977).

${ }^{3}$ Los autores sostienen que el quiebre del sistema monetario internacional se produjo luego de la Segunda Guerra Mundial, cuando la oferta inelástica de oro como medio de pago internacional fue remplazada por una oferta elástica de dólares, a la que después se sumaron unas pocas monedas nacionales de circulación internacional.
} 
fijar la tasa de interés de corto plazo, pues su conexión con la tasa de cambio y las reservas internacionales es menos significativa.

E1 tercer estudio es el de Torija (2014), que distingue entre bancos centrales periféricos (BCP) y bancos centrales del centro (BCC) y analiza las limitaciones de los primeros en materia de política monetaria. Con una sólida fundamentación teórica y empírica, este autor muestra que los BCP renunciaron a la intermediación interna convencional (basada en la financiación del Estado o de los bancos nacionales mediante pasivos monetarios $\mathrm{y}$ no monetarios vis à vis a residentes) y a financiar el desarrollo, y asumieron en cambio la tarea de "reciclar" los flujos internacionales de capital. Desde la óptica de los BCC, esto significa que prestan fondos líquidos a los no residentes, fondos que "retornan" al país invertidos en activos riesgosos; de modo que se abandona progresivamente la misión "desarrollista” para la que fueron creados los BCP en el periodo de entreguerras.

\section{JERARQUÍA DE MONEDAS NACIONALES, DIFERENCIACIÓN DEL CAPITAL Y EXTENSIÓN DE ESAS CONTRIBUCIONES}

El concepto de jerarquía de monedas nacionales no desdeña los aportes existentes. Es, más bien, otro aporte a la discusión que considera la dominación prevaleciente en el sistema monetario internacional e intenta integrar la teoría del dinero internacional a una teoría general del capital recurriendo a la idea de capital diferenciado (Levin, 1997), según la cual la estructura jerárquica de monedas nacionales es parte del proceso histórico de diferenciación del capital. Un proceso en el que las "relaciones económicas" actuales no son relaciones entre iguales y en las que no solo interviene el poder, a diferencia de lo que suponía la teoría económica, sino que ellas mismas reflejan relaciones de poder. E1 mundo de las empresas de capital es jerárquico y heterogéneo, basado en el poder de algunas de ellas para apropiarse sistemáticamente de la capacidad de innovar e impedir que las demás desarrollen esa capacidad (las primeras son las "empresas de capital potenciado" y las segundas, las "empresas de capital simple"; Levin, 1997). Esto pone en cuestión la inexistencia de planificación en el sistema capitalista y muestra, en cambio, que las empresas que adquieren potestad para innovar crean grandes subsistemas de acumulación planificados que trascienden las fronteras nacionales y planifican los procesos productivos de las que carecen de esa capacidad. Mediante esta planificación, la relación entre las empresas deja de ser el contrato jurídico perfecto, el cual es sustituido por el contrato de adhesión, marca a fuego de la relación de poder. 
La idea de que en las relaciones económicas no interviene el poder y que este se deposita en el Estado se derrumba ante esa estructura de poder, y la pregunta relevante es "quién planifica a quién" (Levin, 2004, 2). E1 reconocimiento de esa estructura ofrece un marco más acabado para entender los fenómenos financieros que aquí estudiamos, porque pone en contexto la "jerarquía de monedas nacionales": los Estados que alojan empresas capaces de innovar detentan más poder que los que alojan empresas que solo obedecen y ejecutan procesos reproductivos (Romero, 2012). Un signo de ese poder es su propia moneda, que trae consecuencias como las que describimos en la siguiente sección. Es decir, la "jerarquía de monedas nacionales" es inseparable de la "jerarquía de Estados nacionales". Esta última, envuelta en la estructura de capital que mencionamos, usurpa las funciones del Estado, que pierde soberanía económica, política y jurídica. También las de las demás instituciones públicas e incluso las de las entidades de alcance mundial.

Debido a su poder de planificación, las empresas de capital potenciado pueden delegar simples tareas reproductivas a las empresas de capital simple a través de la tercerización, y obtener los frutos de esas tareas sin comprometer capital, mejorando su tasa de ganancia (Piqué, 2015). En este contexto, las empresas de capital simple, con menor capacidad de acumulación, deben asumir mayores compromisos de capital, lo que reduce aún más su poder de decisión relativo. Este esquema de fuerte acumulación de las empresas de capital potenciado y débil acumulación de las empresas de capital simple da lugar a una mayor capacidad y mejores condiciones de financiación de las primeras (y de los países donde se alojan) y a menor y peores condiciones de financiación de las segundas (y también de los países donde se alojan $)^{4}$. La siguiente sección muestra que los grandes problemas financieros de hoy se entreveran con la relación de poder plasmada en la estructura de financiación y la jerarquía de monedas nacionales.

\section{EL DÓLAR EN LA CÚSPIDE DE LA ESTRUCTURA JERÁRQUICA}

\section{LOS DESEQUILIBRIOS PERMANENTES DE CUENTA CORRIENTE}

Si bien los desequilibrios son comunes en la historia del capitalismo (y desafían una y otra vez las leyes del equilibrio general), los "desequilibrios mundiales de cuenta corriente" que se observan desde finales del siglo pasado han alcanzado tal escala que exigen un estudio profundo, en especial, un estudio que explique sus vínculos con la dinámica

${ }^{4}$ Vaya si la frase "too big to fail", omnipresente en los diarios en el transcurso de la última crisis, no resume esa lógica. 
financiera mundial ${ }^{5}$. Carrera alerta sobre la delicada situación que estos desequilibrios imprimen a la economía mundial:

Por desbalances no entendemos la mera existencia de déficits o superávits de cuenta corriente en un país, sino posiciones de cuenta corriente (y de activos externos) en economías sistémicamente importantes, que conllevan distorsiones significativas respecto a la asignación del ahorro mundial, así como grandes riesgos para la economía internacional derivados de su sostenibilidad $(2009,233)$.

Antes de la década de 2000 ya existían desequilibrios de cuenta corriente, pero fue en esos años cuando cobraron un impulso inédito. Como señala Nudelsman $(2012,157)$, según datos del FMI el déficit de Estados Unidos alcanzó su pico en 2006 y el superávit de China en 2007 ( $6 \%$ y 10,1\% del PIB, respectivamente). En esos mismos años aumentó el superávit de Alemania, Japón y los países exportadores de petróleo y se amplió el déficit de otras economías desarrolladas y algunas economías emergentes europeas ${ }^{6}$.

La aparición y la persistencia de esos desequilibrios suscitaron numerosos argumentos acerca de sus causas posibles. Eichengreen reunió los cuatro más conocidos (que hasta entonces se juzgaban excluyentes) en una simple regla contable:

la cuenta corriente es la diferencia entre el ahorro y la inversión (S - I) y el déficit de Estados Unidos debe ser igual al superávit del resto del mundo $\left(S-I=I^{*}-S^{*}\right)$, donde los asteriscos representan al resto del mundo). En equilibrio general, los choques sobre cualquiera de estas cuatro variables pueden tener implicaciones para todas (2009, 26-27).

E1 primer argumento, esbozado por Roubini y Setser (2004, 21-22), conocido como "ahorro deficiente de Estados Unidos", ponía el acento en "un choque negativo sobre S", impulsado por los déficits fiscales permanentes de la economía estadounidense no compensados por la variación de la inversión. El segundo, propuesto por Cooper (2004), llamado "la nueva economía", se basaba en un "choque positivo sobre I”, causado por el atractivo de la inversión en Estados Unidos a mediados de los noventa debido al alto grado de confianza y a rendimientos mayores que en el resto del mundo. E1 tercero, expuesto por Bernanke (2005), conocido como "exceso de ahorro global", hacía hincapié en un "choque positivo sobre $S^{*}$ " originado por el nuevo manejo de los flujos de capital en el resto del mundo dadas las bajas tasas de interés en Estados Unidos, con la intención de resguardarse de las crisis. E1

\footnotetext{
${ }^{5}$ Nudelsman $(2012,156)$ señala que los desequilibrios de cuenta corriente "constituyen un aspecto crucial de la arquitectura financiera internacional en curso".

6 Bulgaria, Croacia, Eslovenia, España, Estonia, Hungría, Irlanda, Letonia, Lituania, Polonia, Portugal, Reino Unido, República Checa, República Eslovaca, Rumania y Turquía.
} 
cuarto, propuesto por Dooley et al. (2003,3), la "codependencia entre China y Estados Unidos”, era el "choque negativo sobre I*” causado por las políticas chinas encaminadas a acumular reservas (sobre todo en dólares) y la contracción sistemática del déficit de cuenta corriente en Estados Unidos.

Estos cuatro argumentos no solo se enlazan desde la óptica contable sino también cuando se entiende cómo se articulan en el tejido financiero mundial. A este respecto, Portes $(2009,20)$ argumentó que los desequilibrios coincidieron con el crecimiento sin par de la intermediación financiera, reflejado entre otras cosas en la aparición de un sinnúmero de nuevos instrumentos financieros que dieron lugar a un endeudamiento colosal, el llamado "alto apalancamiento". La novedad es que surgieron agudos problemas financieros en economías donde se creía (y se repetía con fines ideológicos) que "el capitalismo siempre funciona bien”. Después de la crisis quedó claro que los activos e intermediarios financieros vinculados a Estados Unidos no eran sostenibles, y se puso en cuestión el ideal de una integración financiera mundial benéfica urbi et orbi que presumían Mendoza et al. $(2007,1)$ y Dooley y Garber $(2005,148)$, cuando previeron una financiación estable de los países emergentes basada en la compra de títulos de la Reserva Federal.

De hecho, la economía estadounidense, en la que los demás países creían encontrar estabilidad y "cumplimiento de las reglas de juego", se valía de los ingresos de capital para financiar su consumo y sus déficits y restringía las posibilidades de las economías emergentes que invertían recursos en esos títulos y no en proyectos de inversión a largo plazo en su propio territorio (Portes, 2009, 22). Como muestra la Financial Services Authority (2009), en ese marco se instala un "nuevo modelo de negocios" de muy corto plazo que propicia la proliferación de instrumentos financieros que devengan retornos superiores a la tasa libre de riesgo y revierten las bajas tasas de interés. Según Obstfeld y Rogoff (2009, 1-2), ese modelo fue aceptado y validado por los Estados nacionales, que empezaron a desentenderse de lo que hasta entonces era una de sus funciones y un imperativo del desarrollo basado en la planificación de largo plazo a cargo de los bancos centrales: regular el sistema financiero para cumplir las metas asignadas en los planes de desarrollo. Ese modelo reforzó los privilegios existentes en el concierto de Estados nacionales. Algunos, como Estados Unidos, sostuvieron sus déficits con endeudamiento externo, ofreciendo activos financieros que los bancos extranjeros compraban rápidamente (algo imposible en los países en desarrollo, 
a los que ante la más mínima duda sobre su capacidad de pago se les niega cualquier préstamo, pequeño o grande). Por su parte, China esterilizó sus crecientes reservas durante lapsos mayores que países de menor poderío económico (como los latinoamericanos, que si esterilizaban reservas advertían peligros económicos). La relación económica entre Estados Unidos y China dio pábulo a la ilusión de "desequilibrios benéficos", pues los países desarrollados se beneficiaban al tomar crédito y los países en desarrollo al invertir sus ahorros en instrumentos de esa economía estable y sólida, ilusión que se derrumbó a mediados de 2007.

El abandono de los bancos centrales de su misión de regular sus sistemas financieros respectivos, en un contexto en el que se ampliaban los nexos financieros internacionales, dio otro aspecto a las crisis y a sus consecuencias. La tenencia de activos internacionales cruzados alcanzó niveles insospechados, así como el número de entidades financieras apalancadas que cobijaban inversiones muy riesgosas que atravesaban varios continentes. Cualquier problema que parecía "circunscrito" a un espacio nacional se convertía en un instante en un problema de alcance mundial. Lo que Krugman $(2009,5)$ llamó "multiplicador financiero internacional" es hoy un aspecto sobresaliente en el contexto financiero mundial. Los sucesos que rodearon a la crisis subprime en Estados Unidos son una prueba rotunda de la veloz mundialización de otros presuntos problemas "locales".

\section{El CONJUNTO HETEROGÉNEO DE BANCOS CENTRALES EN EL SISTEMA MUNDIAL DE RESERVAS BASADO EN EL DÓLAR}

El estudio del impacto de la jerarquía de monedas nacionales en los problemas financieros actuales lleva progresivamente a distinguir aspectos que no son parte del corpus económico "oficial". En particular, la prevalencia de una moneda nacional (el dólar), que implica su capacidad de oficiar como medio de pago y reserva de valor a nivel internacional, reconfigura el sistema financiero internacional, pues se abandona la idea de un mundo donde prevalecen leyes armónicas de equilibrio general cuya premisa es un conjunto de naciones con iguales privilegios, responsabilidades y atribuciones. En realidad, hoy los desequilibrios son permanentes y se entrelazan en una urdimbre de poderes económicos y financieros dispares, donde los activos financieros no tienen fronteras y se redefine la regulación de los sistemas financieros nacionales.

Esa redefinición lleva a poner el acento en una institución que ganó protagonismo desde la segunda posguerra pero que, como ya se 
señaló, a mediados de los setenta empezó a abandonar su misión de regular la actividad financiera nacional para que fuese coherente con los objetivos de desarrollo nacional: el Banco Central. Poner el acento en el Banco Central supone que, así como los Estados nacionales y sus monedas respectivas forman parte de una estructura jerárquica, el mundo de los bancos centrales no es homogéneo; también existe una jerarquía, y algunos pueden cumplir funciones que les están negadas a otros. Las funciones no se limitan a fijar la tasa de cambio y la oferta: también tienen privilegios y capacidades disímiles para manejar las "reservas internacionales" y la deuda ${ }^{7}$. Ejemplos de ello son la capacidad de la economía estadounidense para financiar su consumo y su déficit y la de la economía china para esterilizar las crecientes reservas que ya se comentó.

Desde el final de Bretton Woods, la acumulación de reservas es una pieza de las estrategias cambiarias, y estas un componente de los objetivos de la política nacional. Gradualmente, esos objetivos dejaron de concebirse de la manera prevaleciente en la segunda posguerra, entre otras razones (relevantes para este trabajo), por la irrupción de capitales ávidos de ganancias de cortísimo plazo que trastocaron la armonía financiera imperante hasta entonces. Dichos capitales, que impulsaron las nuevas normas que llevaron a la desregulación nacional, empezaron a propagar las crisis sucesivas. Como muestran Redrado et al. (2006, 29), en ese marco las reservas internacionales empezaron a tener "usos" hasta entonces inexistentes o al menos no tan nítidamente diferenciados. Con esos nuevos "usos", se multiplicaron los estudios sobre las causas de la expansión de la acumulación de reservas en los bancos centrales. La demanda de reservas se solía asociar al motivo de precaución, ante la amenaza de problemas de cuenta corriente. Las crisis asiáticas añadieron los riesgos crecientes en las cada vez más desreguladas cuentas de capital.

Feldstein (1999) intentó explicar algunos rasgos de la nueva lógica nacional de uso de las reservas. A su juicio, las crisis (y su propagación) de finales de los noventa en América Latina, Asia y Rusia mostraron que un episodio crítico no ocurre necesariamente en economías que atraviesen una coyuntura económica especialmente delicada. Esto insta a los países emergentes a resguardarse de cualquier problema que

\footnotetext{
${ }^{7}$ Si bien el estudio completo de estas capacidades disímiles de las instituciones financieras de los Estados nacionales supera el alcance de este artículo, su mención en las noticias diarias no debe causar asombro. En la negociación de la deuda argentina con los acreedores que quedaron fuera del canje (los holdouts o "fondos buitre"), por ejemplo, se puede rastrear cómo ha llegado a ser válido jurídicamente que un problema argentino quede bajo la jurisdicción de un tribunal de Estados Unidos.
} 
pueda provenir de la cuenta capital adquiriendo reservas en moneda extranjera. Esa adquisición es entonces un mecanismo de protección ante cualquier salida abrupta de capitales, como las que ocurrieron a finales del siglo pasado 8 .

Dooley et al. (2003) estudiaron la acumulación de reservas como resultado del régimen cambiario, con base en la experiencia de varios países, sobre todo asiáticos, que atesoraron reservas para controlar la apreciación cambiaria y proseguir la estrategia de crecimiento basada en el crecimiento ampliado de las exportaciones. Aizenman y Lee $(2005,15)$ le dan mayor relevancia al vínculo de las reservas con la expansión del comercio internacional de un país (la "apertura comercial") y al resguardo ante eventuales crisis.

Las estadísticas indican que las reservas no solo crecieron a nivel mundial sino que crecieron más en las economías emergentes. Redrado et al. (2006, 58-70) exploraron las variantes de este fenómeno. Con base en datos de las reservas, e información del régimen cambiario y la política de esterilización, encontraron que existía una acumulación de reservas en el marco de distintos regímenes cambiarios. Si bien en los regímenes cambiarios intermedios o fijos había una acumulación de reservas comprensible, esta era mayor en los regímenes de cambios flotantes, bien fuesen independientes o administrados. Argumentaron entonces que la acumulación de reservas no es un aspecto particular de los regímenes cambiarios fijos y que, una vez iniciada esta política de acumulación, se perpetúa, sin que haya indicios o intentos de abandonarla.

Las características de la acumulación de reservas y de la tasa de cambio en los países en desarrollo en la última década también fueron analizadas por Yeyati et al. (2013), quienes constataron el aumento de las reservas y encontraron que se empleaban para limitar la apreciación de la tasa de cambio más que su apreciación, con la "visión neomercantilista" de mantener depreciada la tasa de cambio real para proteger la industria doméstica.

La preocupación y el empeño de los bancos centrales de los países en desarrollo por armonizar el volumen de reservas, la tasa de cambio y el equilibrio de la balanza de pagos se entienden mejor cuando se consideran las asimetrías del sistema mundial de reservas basado en el dólar. Ocampo $(2010,2)$ analiza los tres principales problemas de este sistema: 1) el acceso desigual a la financiación para los países deficitarios (salvo algunos países con gran poder económico, como

\footnotetext{
${ }^{8}$ Según datos del FMI, las economías en desarrollo de Asia lideraron la compra de reservas internacionales, seguidas por las de Oriente Medio y Norte de África; ver Nudelsman $(2012,161)$.
} 
Estados Unidos) con respecto a los superavitarios. En periodos de crisis, los países deficitarios se ven obligados a contraer las principales variables económicas por falta de financiación, mientras que los países superavitarios continúan su curso normal; 2) la inestabilidad ocasionada por el dominio mundial de una moneda nacional. Esta situación cuestiona el dilema de Triffin, según el cual si se agotasen las reservas de oro de Estados Unidos, este país se vería obligado a ejecutar políticas contraccionistas y a reducir la liquidez a nivel mundial. Hoy no parece haber impedimentos para la creación de liquidez internacional a partir de los déficits sostenidos de la economía estadounidense. A este respecto, Nudelsman (2012) señala que la confianza en el dólar es una pieza central de los ciclos económicos a nivel mundial; 3) la desigualdad de las relaciones financieras internacionales. Los países en desarrollo, ansiosos de acumular reservas comprando activos emitidos por Estados Unidos, proporcionan fondos a ese país a tasas de interés bajas. Esta relación perjudicial se agudiza porque los flujos de capital crecen en periodos de expansión y se contraen en periodos de recesión.

\section{LA CRISIS DE 2007-2008 Y LAS INSTITUCIONES FINANCIERAS}

En los apartados anteriores dimos las primeras pinceladas de una imagen de la dinámica financiera contemporánea. Esas primeras pinceladas no son casuales, están teñidas por las continuas advertencias de que el "sistema económico" no puede continuar el curso que ha seguido hasta ahora o, en términos más explícitos, que los recursos propios no se pueden seguir delegando a capitales que solo buscan la valorización de corto plazo.

El colapso de mediados de 2007 y sus secuelas generaron una crisis en todo el mundo, pero el análisis de la dinámica económica, financiera y política anterior (en especial de los últimos quince años) indica que la crisis no fue intempestiva sino que es parte del proceso de diferenciación del capital en el que las instituciones políticas y económicas parecen ser lo que no son. Hoy los Estados no son igualmente soberanos, no todas las monedas nacionales pueden cumplir las funciones convencionales, no todos los bancos centrales tienen autonomía para regular su sistema financiero (p. ej., para manejar sus reservas y la tasa de cambio). Y los déficits, superávits y deudas de las economías nacionales no tienen iguales consecuencias.

El estudio de los desequilibrios de cuenta corriente así lo constata. Como hemos visto, la economía estadounidense se favorece con la diferencia entre la tasa de interés que paga por sus compromisos externos y la tasa de retorno que recibe por sus inversiones externas. 
Esa diferencia, reforzada por la ansiosa compra de sus títulos de deuda por los bancos extranjeros, le ha permitido financiar su prolongado déficit, y esa situación asimétrica se consolidó con el crecimiento de las economías emergentes, que elevó la demanda de reservas en dólares y la compra de títulos estadounidenses. El déficit permanente de la economía estadounidense no le ha restado poder internacional al dólar. Su capacidad para ser reserva de valor y medio de pago a nivel mundial induce una demanda de reservas en dólares que se mantienen en depósitos o activos con bajas tasas de interés y, como señala Nudelsman $(2012,167)$, fortalece el papel de Estados Unidos como "banquero más importante del mundo". Así, puesto que el sistema de reservas se basa en el dólar, Estados Unidos puede, en principio, decidir su política monetaria e imponerla a nivel internacional. Como señala Ocampo (2009, 2-5), debido a la percepción de que los bonos de la FED son los activos más seguros a nivel mundial, se relaja la presión sobre la tasa de interés estadounidense, que "debería” seguir el curso de los movimientos de la tasa de cambio del dólar con respecto a otras monedas.

Ese juego recíproco entre los países compradores de títulos de la Reserva Federal y la economía estadounidense desmorona otro "deber ser” convencional de la dinámica económica, que en la literatura se conoce como "ayuda inversa". A saber, que la creciente acumulación de reservas en las economías en desarrollo es una manera de "autoasegurarse" o "autoprotegerse" de los capitales ávidos de valorizarse en el muy corto plazo que circulan en el sistema financiero mundial y se reproducen con rapidez en periodos de crecimiento. Ese "autoseguro" daría a estas economías la posibilidad de seguir políticas anticíclicas de corto plazo y resguardarse en un sistema en el que no hay ningún "seguro colectivo". Pero los efectos no son benéficos para estas economías. Ocampo (2009, 3-12) argumenta que la acumulación de reservas supuestamente benéfica es una falacia de composición cuando se considera a nivel mundial, es decir, un razonamiento que atribuye al todo propiedades de sus partes. Además, esta acumulación no carece de costos. Rodrik (2006) es muy claro cuando señala que cada dólar de reservas que los bancos centrales mantienen en títulos de corto plazo de bajos rendimientos del tesoro de Estados Unidos tiene un costo de oportunidad igual al costo del endeudamiento externo o a la tasa social de retorno de la inversión en esas economías.

En la imaginación popular, la supuesta igualdad de las economías nacionales solía ir acompañada de instituciones financieras internacionales que garantizaban la estabilidad financiera mundial siempre 
dispuestas a socorrer a todas las naciones por igual. Esa era la misión que se asignó al FMI y a los bancos multilaterales. Pero no han ejercido esa función en igualdad de condiciones. Como muestran Izquierdo y Talvi (2010), en la crisis reciente dieron amplio apoyo y sin condiciones a las economías desarrolladas, mientras que cuando ha habido crisis en los países en desarrollo o en las economías emergentes se les ha retirado la "ayuda financiera internacional" o impuesto duras condiciones (p. ej., en Argentina en 2001). Lo que constata el "acceso desigual a la financiación" que ya se mencionó.

La delicada situación que atraviesa el sistema financiero mundial (incluidas sus instituciones) ha provocado el surgimiento de numerosas iniciativas de reforma. Para Greenwald y Stiglitz (2010) la estabilidad y el equilibrio son características clave de un sistema de pagos ideal, donde estabilidad significa tasas de cambio que no tengan grandes variaciones y una rápida disipación de crisis repentinas, y equilibrio la atenuación de los desequilibrios permanentes de cuenta corriente. Estas características llevarían a una movilidad de capitales más eficiente. Dado que el sistema actual no tiene esas características, propusieron un esquema de reformas con distintos niveles de alcance. Las reformas de alcance moderado consisten en ampliar el sistema de derechos especiales de giro. Las de mayor impacto incluyen la posibilidad de emitir montos variables según las condiciones de la economía mundial, el uso de fondos para bienes públicos mundiales, el diseño de incentivos para evitar desequilibrios sistemáticos y la creación de una nueva estructura institucional consistente con el nuevo sistema mundial de reservas. Esta propuesta fue desestimada por Eichengreen (2011) con el argumento de que los derechos especiales de giro se limitan a liquidar compromisos de deuda entre los Estados nacionales y el FMI, y no se pueden utilizar para transacciones entre países ni como unidad de denominación de los bonos internacionales.

Fanelli (2010,2-13), por su parte, subraya la necesidad de establecer un nuevo conjunto de reglas para el sistema financiero mundial. Propone buscar una "solución cooperativa" que remedie los problemas del sistema financiero actual. Como señala Nudelsman, asigna a la "comunidad internacional" la tarea de

diseñar y hacer cumplir estructuras de gobierno capaces de facilitar las operaciones financieras internacionales entre las partes, asegurar la consistencia entre las estructuras regulatorias domésticas e internacionales, asegurar que las operaciones financieras internacionales mejoren la provisión de liquidez internacional y la capacidad de las autoridades para manejar la política económica (2012, 169). 
Esas iniciativas para modificar el sistema financiero internacional podrían ser enriquecidas con una visión teórica actualizada del sistema capitalista en su conjunto que parece necesaria para prefigurar una política económica cualitativa. La tarea es enorme y quizá obra de toda una generación, pero vale la pena empeñarse en ella.

\section{REFERENCIAS BIBLIOGRÁFICAS}

1. Aizenman, J. y J. Lee. "International reserves: Precautionary versus mercantilist views, theory and evidence", NBER working paper 11366, 2005.

2. Bernanke, B. "The global saving glut and the U.S. current account deficit", Washington DC, Junta de Gobernadores de la Reserva Federal, 10 de marzo de 2005.

3. Carrera, J. "E1 G20, la crisis y el rediseño de la arquitectura financiera internacional”, Ensayos Económicos 53-54, 2009, pp. 217-244.

4. Cooper, R. "US deficit: It is not only sustainable, it is logical", Financial Times, Londres, 31 de octubre de 2004.

5. Dooley, M.; D. Folkerts-L. y P. Garber. "An essay on the revived Bretton Woods System”, NBER working paper 9971, 2003.

6. Dooley, M. y P. Garber. "Is it 1958 or 1968? Three notes on the longevity of the revived Bretton Wood System”, Brookings Papers on Economic Activity 36, 1, Washington DC, 2005, pp. 147-210.

7. Eichengreen, B. "La parábola de los ciegos y el elefante", Ensayos Económicos 53-54, 2009, 25-57.

8. Eichengreen, B. Exorbitant privilege - The rise and the fall of the dollar, Nueva York, Oxford University Press, 2011.

9. Fanelli, J. "The international financial architecture and global institution building. A Latin American view", seminario regional, The Impact of the Global Economic Crisis, Woodrow Wilson International Center for Scholars, Washington DC, 2010.

10. Feldstein, M. "Self-protection for emerging market economies", NBER working paper 6907, 1999.

11. Financial Services Authority. "What went wrong?", The Turner Review. A regulatory response to the global banking crisis, Londres, FSA, 2009, pp. 1-49.

12. Frenkel, R. y M. Rapetti. "Flexibilidad cambiaria y acumulación de reservas en América Latina”, Iniciativa para la Transparencia Financiera, documento No. 50, Buenos Aires, 2009.

13. García B., A.; L. Mata M. y E. Nell. "Asimetrías monetarias internacionales y Banca Central”, Investigación Económica 265, 2008, pp. 145-187.

14. Gourinchas, P. O. y H. Rey. "From world banker to world venture capitalist: US external adjustment and the exorbitant privilege”, NBER working paper 11563, 2005.

15. Greenwald, B. y J. E. Stiglitz "A modest proposal for international monetary reform', S. Griffith-J. et al., eds., Time for a visible hand - Lessons from the 2008 world financial crisis, Nueva York, Oxford University Press, 2010, pp. 314-344. 
16. Izquierdo, A. y E. Talvi. The aftermath of the crisis: Policy lessons and challenges ahead for Latin America and the Caribbean, Washington DC, IADB, 2010.

17. Keynes, J. M. Teoría general de la ocupación, el interés y el dinero [1936], Buenos Aires, Fondo de Cultura Económica, 1992.

18. Krugman, $\mathrm{P}$. The return of depression economics and the crisis of 2008, Nueva York, Norton \& Company, 2009.

19. Kydland, F. y E. Prescott. "Rules rather than discretion: The inconsistency of optimal plans", Journal of Political Economy 85, 3, 1977, pp. 473-492.

20. Levin, P. El capital tecnológico, Buenos Aires, Editorial Cooperativas, 1997.

21. Levin, P. "El progreso social desde la perspectiva del tercer sector. ¿Quién planifica a quién?”, documentos del CEPLAD, Buenos Aires.

22. Lucas, R. E. "Econometric policy evaluation: A critic", Carnegie Rochester Conference Series on Public Policy 1, 1976, pp. 19-46.

23. Mendoza, E. et al. "Financial integration, financial deepness, and global imbalances", NBER working paper 12909, 2007.

24. Nudelsman, S. "Los desequilibrios globales, el G20 y la cooperación internacional", Revista Estudios 21, 43, 2012, pp. 155-174.

25. Nudelsman, S. "Implicaciones de la crisis financiera y económica global en América Latina”, Problemas del Desarrollo 174, 44, 2013, pp. 125-146.

26. Obstfeld, M. y K. Rogoff. "Global imbalances and the financial crisis: Products of common causes”, Federal Reserve Bank of San Francisco, octubre de 2009, pp. 131-172.

27. Ocampo, J. A. "Implicaciones de política económica de la inestabilidad financiera actual”, Ensayos Económicos 53-54, 2009, pp. 191-215.

28. Ocampo, J. A. "Building an SDR based global reserve system”, Journal of Globalization and Development 1, 2, 2010, pp. 1-24.

29. Olivera, J. H. "A note on the optimal rate of growth of international reserves", Journal of Political Economy 77, 1969, pp. 245-248.

30. Olivera, J. H. "Dinero pasivo internacional y hegemonía monetaria”, Desarrollo Económico XXIII, 89, 1983, pp. 1-7.

31. Piqué, P. "Sistema nacional de innovación y planificación de los subsistemas de capital. La política tecnológica como capítulo de una estrategia de desarrollo en el presente latinoamericano", Enfoques XXVII, 1, 2015, pp. 143-162.

32. Portes, R. "Global imbalances”, M. Dewatripont et al., eds., Macroeconomic stability and financial regulation: Key issues for the G2O, Londres, Centre for Economic Policy Research, 2009, pp. 19-27.

33. Redrado, M. et al. "La política económica de la acumulación de reservas: una nueva evidencia internacional”, documento de trabajo No. 14, Banco Central de la República Argentina, 2006.

34. Rodrik, D. "The social cost of foreign exchange reserves", International Economic Journal 20, 3, 2006, pp. 253-266.

35. Romero, V. "La soberanía del Estado nación desde la perspectiva de la economía política”, documentos del CEPLAD, Buenos Aires, 2012. 
36. Roubini, N. y B. Setser. "The US as a net debtor: The sustainability of the US external imbalances", Universidad de Nueva York, 2004, [http://people.stern.nyu.edu/nroubini/papers/Roubini-Setser-USExternal-Imbalances.pdf].

37. Sargent, T. J. y N. Wallace. "Rational expectations, the optimal monetary instrument, and the optimal money supply rule", Journal of Political Economy 83, 2, 1975, pp. 241-254.

38. Stiglitz, J. y B. Greenwald. "Towards a new global reserve system", Journal of Globalization and Development 1, 2, 2010, pp. 1-24.

39. Torija Z., E. "Bancos centrales 'periféricos: el caso de América Latina”, conferencia en el Instituto de Investigaciones Económicas, Universidad de Buenos Aires, 2014.

40. Woodford, M. "Revolution and evolution in twentieth-century macroeconomics", 1999, [http://www.columbia.edu/ mw2230/macro20C. $\mathrm{pdf}]$. 